kinase $C$ in vitro is directly related to the state of kernicterus remains unclear from our present results. We failed to demonstrate an in vivo effect of bilirubin on the specific activity of protein kinase $C$ in adult Sprague-Dawley rats (data not shown). However, kernicterus is confined to the very early neonatal period or low birth weight infants; acidosis or hypoalbuminemia also tend to occur in such patients. Acidosis or hypoalbuminemia increases unbound bilirubin levels allowing the accumulation of bilirubin in central nervous tissues (17). Therefore, experiments using premature or very early neonatal animals with hyperbilirubinemia are necessary in order to clarify precisely the role of protein kinases in kernicterus.

\section{REFERENCES}

1. Karp WB 1979 Biochemical alterations in neonatal hyperbilirubinemia and bilirubin encephalopathy. Pediatrics 64:361-368

2. Nestler EJ, Greengard P 1983 Protein phosphorylation in the brain. Nature 305:583-588

3. Nishizuka Y 1984 The role of protein kinase $C$ in cell surface signal transduction and tumor promotion. Nature 308:693-698.

4. Constantopoulos A, Matsaniotis N 1976 Bilirubin inhibition of protein kinase: its prevention by cyclic AMP. Cytobios 17:17-20

5. Kikkawa U, Takai Y, Minakuchi R, Inohara S, Nishizuka Y 1982 Calciumactivated, phospholipid-dependent protein kinase from rat brain. J Biol Chem 257:13341-13348

6. Hashimoto E, Takeda M, Nishizuka Y, Hamana K, Iwai K 1976 Studies on the sites in histones phosphorylated by adenosine $3^{\prime}: 5^{\prime}$-monophosphate- dependent and guanosine $3^{\prime}: 5^{\prime}$-monophosphate-dependent protein kinase. J Biol Chem 251:6287-6293

7. Folch J, Lees M, Stanley GHS 1957 A simple method for the isolation and purification of total lipides from animal tissues. J Biol Chem 226:497-509

8. Glynn IM, Chappell JB 1964 A simple method for the preparation of ${ }^{32} \mathrm{P}$ labeled adenosine triphosphate of high specific activty. Biochem J 90:147149

9. Lowry OH, Rosebrough NJ, Farr AL, Randall RJ 1951 Protein measurement with the folin phenol reagent. J Biol Chem 193:265-275

10. Takai Y, Kishimoto A, Kikkawa U, Mori $\Upsilon$ Nishizuka Y 1979 Unsaturated diacylglycerol as a possible messenger for the activation of calcium-activated, phospholipid-dependent protein kinase system. Biochem Biophys Res Commun 91:1218-1224

11. Kishimoto A, Takai Y, Mori T, Kikkawa U, Nishizuka Y 1980 Activation of calcium and phospholipid-dependent protein kinase by diacylglycerol, its possible relation to phosphatidylinositol turnover. J Biol Chem 255:22732276

12. Ostrow JD, Schmid R 1963 The protein-binding of $\mathrm{C}^{14}$-bilirubin in human and murine serum. $J$ Clin Invest 42:1286-1299

13. Mori T, Takai Y, Minakuchi R, Yu B, Nishizuka Y 1980 Inhibitory action of chlorpromazine, dibucaine, and other phospholipid-interacting drugs on calcium-activated, phospholipid-dependent protein kinase. J Biol Chem $255: 8378-8380$

14. Mustafa MG, King TE 1970 Binding of bilirubin with lipid. J Biol Chem 245:1084-1089

15. Michell RH 1975 Inositol phospholipids and cell surface receptor function. Biochim Biophys Acta 415:81-147

16. Eriksen EF, Danielsen H, Brodersen R 1981 Bilirubin-liposome interaction. J Biol Chem 256:4269-4274

17. Diamond I, Schmid R 1966 Experimental bilirubin encephalopathy. The mode of entering of bilirubin- ${ }^{-14} \mathrm{C}$ into the central nervous system. $\mathrm{J}$ Clin Invest 45:678-689

\title{
Unsuccessful Attempts to Induce Peroxisomes in Two Cases of Zellweger Disease by Treatment with Clofibrate
}

\author{
INGEMAR BJÖRKHEM, SVANTE BLOMSTRAND, HANS GLAUMANN, AND \\ BIRGITTA STRANDVIK \\ Department of Clinical Chemistry at the Karolinska Institute, Huddinge Hospital, Huddinge, Department of \\ Pediatrics, Borås Hospital, Borås, Departments of Pathology and Pediatrics at the Karolinska Institute,
} Huddinge Hospital, Huddinge, Sweden

\begin{abstract}
The cerebro-hepato-renal syndrome of Zellweger is a fatal hereditary disease and most of the affected infants die before the age of 6 months. Most probably the fatal outcome of the disease is due to an apparent complete lack of peroxisomes in the liver, kidneys, and brain. Treatment with clofibrate is known to increase drastically the number of peroxisomes in mammalian liver. We therefore treated two infants with the Zellweger syndrome with clofibrate (30 and $45 \mathrm{mg} / \mathrm{kg}$ body weight, respectively) for 3-4 wk. No clinical effect of the treatment was observed in any of the two cases, and the pattern of abnormal bile acids in serum did not change. No peroxisomes could be
\end{abstract}

Received October 22, 1984; accepted February 4, 1985

Requests for reprints should be addressed to Dr. Ingemar Björkhem, Department of Clinical Chemistry I, Huddinge Hospital, S-14186 Huddinge, Sweden. Supported by the Swedish Medical Research Council Projects 3141, 3492, and 5361 . detected by electron microscopy of liver biopsies taken immediately after the treatment. Our failure to induce peroxisomes in the two Zellweger patients is in accord with the hypothesis that the protein missing in this autosomal recessive disease is absolutely essential for the formation of peroxisomes. (Pediatr Res 19: 590-593, 1985)

The Zellweger syndrome is a fatal hereditary disease characterized by craniofacial malformations, hypotonus, liver enlargement, renal cysts, central nervous disturbances, and mental retardation (1). In general affected infants die before 6 months of age. The most characteristic histological finding in this disease is an apparently complete absence of peroxisomes in the liver and kidneys (2). Goldfischer et al. (2) have also demonstrated 
mitochondrial abnormalities and a defect in the mitochondrial electron transport chain. In some cases, the mitochondria seem to be normal, however, and it has been suggested that the mitochondrial changes are secondary to the lack of peroxisomes (3). The autosomal recessive inheritance of the Zellweger syndrome suggests that it is an inborn error of metabolism affecting one specific protein. On the other hand, it is difficult to understand the apparently complete absence of a cell organelle as a consequence of only one missing protein. One can only speculate that the missing protein may have a regulatory function, maybe necessary for the biogenesis of peroxisomes, or maybe an essential component for membrane synthesis.

Treatment with clofibrate is known to increase drastically the number of peroxisomes in mammalian liver (4). Although the mechanism of this induction is not known, it has been shown that clofibrate induces mRNA for four peroxisomal enzymes (5). It was also recently reported that three clofibrate-sensitive peroxisomal enzymes are synthesized on free polysomes, released into the cytosol, and then transported into peroxisomes (6). If the specific protein missing in the Zellweger disease is absolutely essential for the biogenesis of peroxisomes, treatment with clofibrate cannot be expected to have any effect on the disease. If, however, there is a small number of hitherto undetected peroxisomes in the hepatocytes of affected infants, it should be possible to increase the number of the organelle by treatment with clofibrate. Such an effect may also improve the condition of the patient, although the damage to the central nervous system most probably is irreversible.

Herein, we report unsuccessful attempts to induce peroxisomes in the liver of two infants with the Zellweger syndrome.

\section{MATERIALS AND METHODS}

Case 1. This case was the first infant born to healthy young parents without consanguinity. Due to prolonged delivery this was completed with vacuum extraction. The infant, a girl, was born after $40 \mathrm{wk}$ of gestation, birth weight was $2860 \mathrm{~g}$, and length was $49 \mathrm{~cm}$. At birth the dysmorphic features were noticed, and the infant had profound hypotonia. In addition to the typical abnormal skull shape and appearance of Zellweger disease, ultrasonic investigation showed enlargement of the liver. X-ray showed the typical calcification of patellae and acetabulum, and the patient had congenital glaucoma and pathological EEG with pathological visual evoked response. Laboratory investigations showed normal values except for increased serum concentrations of transaminases (ASAT $3.4 \mathrm{ukat} / \mathrm{L}$, ALAT $2.6 \mathrm{ukat} / \mathrm{L}$ ) and serum lactate dehydrogenase ( $26 \mathrm{ukat} / \mathrm{L})$. There was a slight transient hyperbilirubinemia during the first weeks, and the serum transaminases increased further to 14 and 10 ukat/L, respectively. There was no increased level of pipecolic acid in the urine. The diagnosis was verified by high serum concentrations of trihydroxycoprostanic acid $(7,8)$ and the typical $\mathrm{C}_{29}$-dicarboxylic acid (8). A tissue culture of fibroblasts from the patient showed increased levels of very long-chain fatty acids ( 9 , 10). The patient had frequent short-lasting convulsions which were not cured by phenobarbital treatment but reduced the frequency.

The infant gradually deteriorated and died at the age of $41 / 2$ months. No autopsy was performed according to the wishes of the parents.

Case 2. This case was a boy, the third child born to healthy parents with no consanguinity. The firstborn sibling was healthy, but the other sibling died at 1 wk of age with multiple malformations: hydrocephalus, pes equinovarus, micrognatia, retentio testis, and cystic kidneys. The present child was born after $39 \mathrm{wk}$ of gestation at normal delivery. The birth weight was $2850 \mathrm{~g}$ and the length was $49 \mathrm{~cm}$. At birth the child had tachycardia, areflexia, profound hypotonia, and there was no spontaneous respiration. He was intubated and immediately transferred to a respirator in which he was treated with oxygen supply. There were extensive pulmonary infiltrations considered to be due to adaptive disturbances. The child had the typical facial appearance of Zellweger disease, abnormal skull shape, epicanthus, and was also hypotonic. Ultrasonic investigation showed dilatation of the lateral and third ventricles of the brain and also suspect renal cortical cysts. Intravenous urography was normal. The patient improved, and the oxygen supply could be gradually decreased. After $2 \frac{1}{2}$ months of age the infant was kept in bed. EEG was pathological with a pathological result of visual evoked response. Despite the continuous profound hypotonus and hyporeflexia, the diagnosis was not proved until 3 months later. Increased levels of pipecolic acid was not found in the urine, but the serum contained high levels of trihydroxycoprostanoic acid and the typical $\mathrm{C}_{29}$-dicarboxylic acid $(7,8)$.

The frequency of general convulsions increased despite anticonvulsive therapy, and the patient died at 5 months of age due to interstitial pneumonia. A liver biopsy was taken within 30-60 min after death. Renal cortical cysts, liver steatosis, and a slight atrophy of the adrenals were found at autopsy.

Ethical aspects. Treatment with clofibrate was approved by the local ethical committee of the Karolinska Institute at Huddinge University Hospital.

Histological methods. Needle biopsy was performed according to Menghini (11). For light microscopy specimens were fixed in Histofix and embedded in paraffin and Eponaraldite. Sections were stained with hemotoxylin and eosin, periodic acid-Schiff, Perl's iron, and reticulin. For electron microscopy randomly chosen $1-\mathrm{mm}^{3}$ cubes of liver were fixed in $2 \%$ glutaraldehyde containing $0.1 \mathrm{M}$ cacodylate buffer $(\mathrm{pH} 7.4)$ and $0.1 \mathrm{M}$ sucrose. The liver samples were postfixed in $1 \%$ osmium tetroxide, dehydrated in graded ethanol solutions, and embedded in LX $1: 2$ resin. En bloc staining was performed with uranyl acetate added to the final ethanol solution. Thin sections were stained with lead citrate.

For ultrastructural demonstration of catalase, slices were sectioned from frozen glutaraldehyde fixed tissue and incubated with DAB at $\mathrm{pH} 10.0$ according to the procedure of Novikoff $e t$ al. (12). Incubation was performed for 30 and $60 \mathrm{~min}$ at $37^{\circ} \mathrm{C}$. The slices were curled, embedded, and processed as above. As control specimens, liver biopsy material from a healthy 2 -yr-old child was used.

\section{RESULTS AND DISCUSSION}

Case 1 was treated with clofibrate in a dose of $30 \mathrm{mg} / \mathrm{kg}$ body weight daily for 4 wk prior to death, and case 2 with $45 \mathrm{mg} / \mathrm{kg}$ body weight daily for $3 \mathrm{wk}$ prior to death. No clinical effect of the treatment was observed in any of the two cases. The pattern of abnormal bile acids in serum $(7,8)$ did not change during the treatment. Needle liver biopsies were taken immediately before the treatment and immediately after death.

According to light microscopical findings, the histological appearance of all liver biopsies was essentially normal except for focal areas of hepatocyte rosette formation, discrete fibrosis, and inflammation in the portal areas as well as some Kupffer cell siderosis. Following clofibrate treatment, some small intracytoplasmatic lipid droplets $(2 \mu \mathrm{m})$ were noticed in periportal hepatocytes as well as mild portal roundcell infiltration. Both phenomena are probably due to the treatment and have been seen also in adults given clofibrate or similar drugs (Björkhem I, Blomstrand S, Glaumann H, Strandvik B, unpublished observation).

According to examinations by transmission electron microscopy, the general appearance of the hepatocytes was quite normal (Fig. 1a). However, mitochondrial irregularities were present, eg, disturbed orientation of the cristae, focal electron-dense deposits, and rounded swollen shapes. Similar alterations have been described in other pathological conditions including $\alpha$-1-antitrypsin deficiency (11). No peroxisomes could be found in the hepatocytes. This was confirmed by enzyme histochemistry which also 


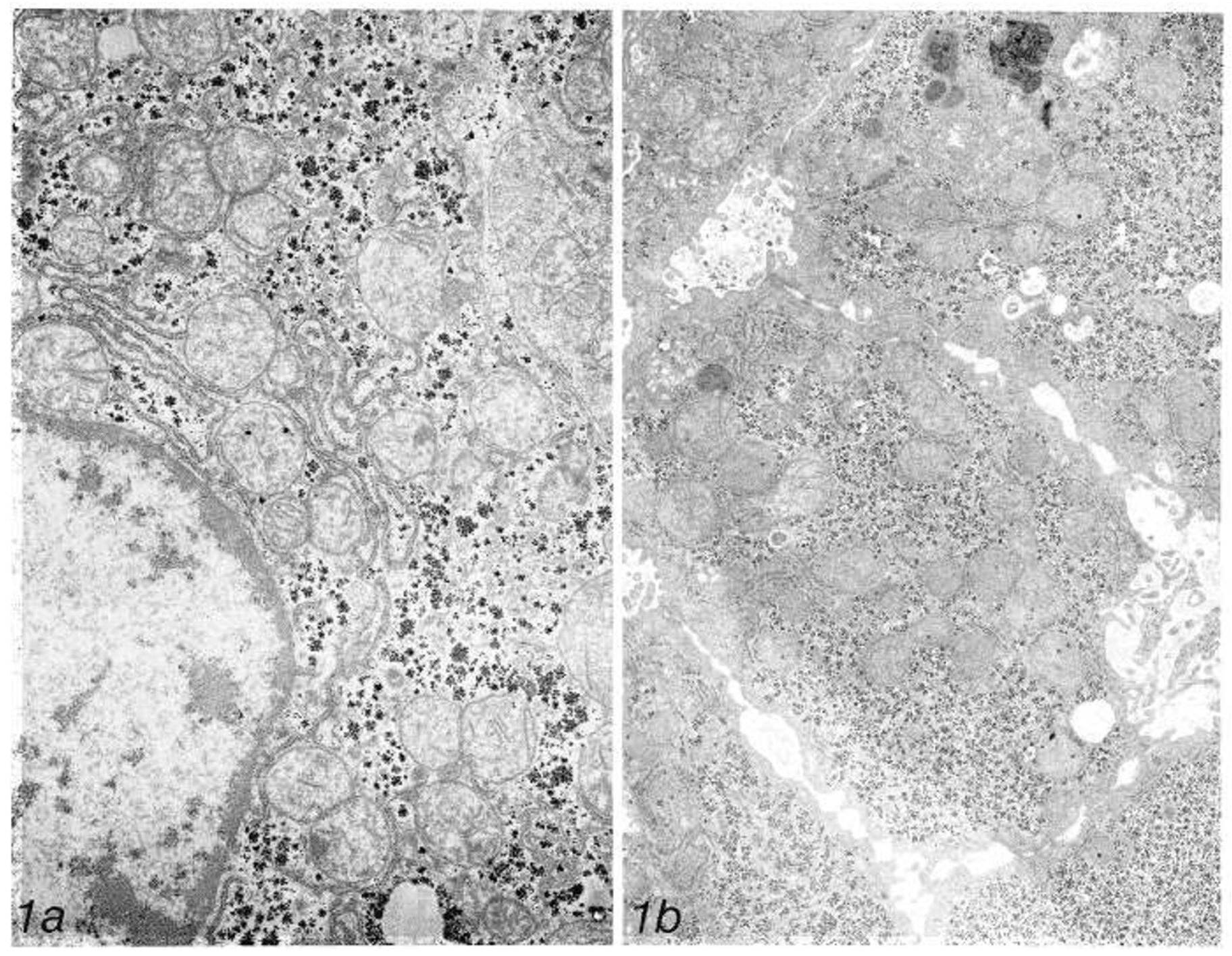

Fig. 1. Electron microscopy of liver biopsies from case 2 before $(a)$ and after $(b)$ clofibrate treatment. Note absence of peroxisomes. For explanation see the text.
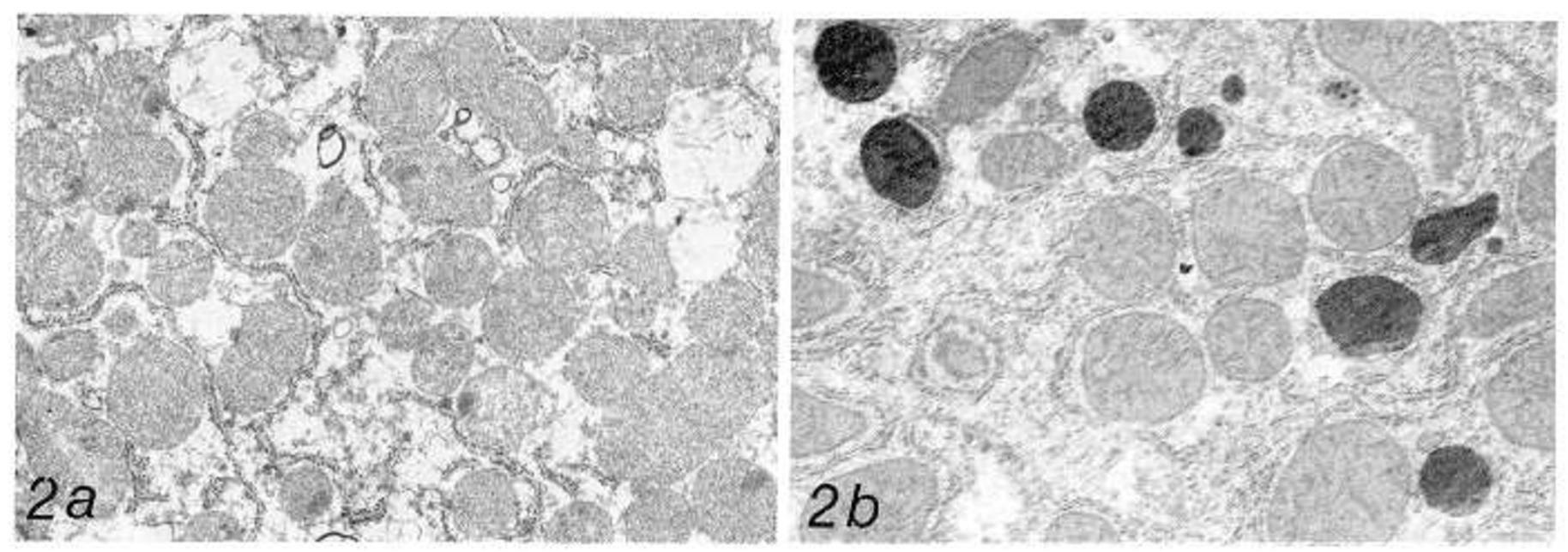

Fig. 2. Electron micrographs from case 2 following clofibrate treatment $(a)$ and control liver from a kidney donor $(b)$ incubated for histochemical demonstration of catalase. The liver tissue was in both cases obtained about $0.5-1 \mathrm{~h}$ postmortem fixed, frozen, and sectioned. Incubation was performed in alkaline DAB. Note absence of peroxisomes in $a$ (clofibrate treatment of case 2 ) in contrast to the prominent staining of peroxisomes of control liver in $b$. 
disclosed absence of microperoxisomes. In the control samples numerous peroxisomes $(0.6 \mu \mathrm{m})$ were seen together with a few small dense-staining microperoxisomes scattered in the cytoplasm. The latter particles were characterized by a dense matrix surrounded by a lucent or "empty" halo. In the samples from the patients there were autophagic vacuoles in various stages of development and abundant residual bodies. Compared to the control samples, the Golgi complex was difficult to recognize, although present.

Clofibrate treatment did not result in occurrence of detectable peroxisomes or microperoxisomes (Fig. 1b). Enzyme histochemistry substantiated this conclusion (Fig. 2a). This absence of peroxisomes was not due to postmortem artefacts, since in liver tissues from kidney transplant donors taken $1 \mathrm{~h}$ after circulatory arrest, peroxisomes were easily identified (Fig. $2 b$ ). However, the treatment seemed to cause some enlargement of occasional mitochondria, vesiculation of their cristae, and scattered lipid inclusion bodies in the cytoplasm.

Our failure to induce peroxisomes in the two Zellweger patients is in accordance with the hypothesis that the protein missing in this disease is absolutely essential for the formation of peroxisomes. It cannot be completely excluded, however, that an earlier postnatal treatment would have had an effect.

\section{REFERENCES}

1. Bowen P, Lee CSN, Zellweger H, Lindenberg R 1961 A familial syndrome of multiple congenital defects. Bull Johns Hopkins Hosp 114:402-414
2. Goldfischer S, Moore CL, Johnson AB, Spiro AJ, Valsamis MP, Wisniewski HK, Ritch RH, Norton WT, Rapin I, Gartner LM 1973 Peroxisomal and mitochondrial defects in the cerebro-hepato-renal syndrome. Science 182:62-64

3. Borst P 1983 Animal peroxisomes, lipid biosynthesis and the Zellweger syndrome. Trends Biochem Sci:269-272

4. Lazarow $\mathrm{PB}$, DeDuve $\mathrm{C} 1976 \mathrm{~A}$ fatty acid-CoA oxidizing system in rat liver peroxisomes, enhancement by clofibrate, a hypolipidemic drug. Proc Natl Sci USA 73:2043-2046

5. Chatterjee B, Demyan WF, Lalwani ND, Reddy JK, Roy AK 1983 Reversible alteration of hepatic messenger RNA-species for peroxisomal and nonperoxisomal proteins induced by the hypolipidemic drug WY-14, 643. Biochem J 21 4:879-883

6. Miura S, Mori M, Takiguchi M, Tatibana M, Furuta Muazawa S, Hashimoto T 1984 Biosynthesis and intracellular transport of enzymes of peroxisomal $\beta$-oxidation. J Biol Chem 259:6397-6402

7. Hanson RF, VanLeeuwen PS, Williams GC, Grabowski G, Sharp HL 1978 Defects of bile acid synthesis in Zellweger's syndrome. Science 203:11071108

8. Parmentier GG, Janssen GA, Eggermont EA, Eyssen HJ $1979 \mathrm{C}_{27}$-Bile acids in infants with coprostanic acidemia and occurrence of a $3 \alpha, 7 \alpha, 12 \alpha$ trihydroxy- $5 \beta-C_{29}$ dicarboxylic bile acid as a major component in their serum. Eur J Biochem 102:173

9. Björkhem I, Sisfontes L, Boström B, Kase B, Hagenfeldt L, Blomstrand R 1984 Possibility of prenatal diagnosis of the Zellweger syndrome. Lancet 1:1234-1235

10. Brown I, McAdams AJ, Cummins JW, Konkol R, Sing I, Moser AB, Moser HW 1982 Cerebro-hepato-renal (Zellweger) syndrome and neonatal adrenoleukodystrophy: Similarities in phenotype and accumulation of very long chain fatty acids. Gen Clin Johns Hopkins Hosp 151:344-361

11. Nemeth A, Strandvik B, Glaumann H 1983 Alpha-1-antitrypsin deficiency and juvenile liver disease. Virchows Arch Cell Pathol 44:15-33

12. Novikoff AB, Novikoff PM, Davis C, Nelson Q 1972 Studies on microperoxisomes. A cytochemical method for light- and electron microscopy. $\mathrm{J}$ Histochem Cytochem 20:1006-1023

\title{
Growth and Development of Pediatric Research ${ }^{1}$
}

\author{
E. RICHARD STIEHM
}

Department of Pediatrics, UCLA School of Medicine, Los Angeles, California 90024

\begin{abstract}
Pediatric research may be entering a period of failure to thrive. This is despite impressive scientific achievements, significant financial benefits, intriguing unanswered questions and a rewarding life for the pediatric researcher. Many of the difficulties are financial and situational, including small departments and divisions, few pediatric research mentors, impecunious pediatric hospitals and services, ethical constraints on pediatric research and competing responsibilities. Grants to pediatric departments represent about $3 \%$ of the total NIH research project support. The two largest federal programs supporting Pediatric Research are the Clinical Research Center (CRC) program $(20 \%$ of an $\$ 28,000,000 / y r$ budget) and the $\mathrm{Na}-$ tional Institutes of Child Health and Human Development (17\% of a $\$ 123,000,000 / y r$ budget). There are 75 CRCs of which 60 admit children; 10 CRCs are in children's hospital and 6 other CRCs have a clear pediatric focus. Pediatric Departments receive $3 \%$ of $\mathrm{NIH}$ funds; this represents
\end{abstract}

Reprint requests E. Richard Stiehm, M.D., Professor of Pediatrics, UCLA School of Medicine, Los Angeles, CA 90024.

'Presidential Address, Western Society of Pediatric Research Carmel, CA, February 1984
$10 \%$ of funds to clinical departments. By contrast medicine departments receive $17 \%$ of NIH funds $(47 \%$ of funds to clinical departments). NIH research support to pediatrics $(\$ 82,000,000 / y r)$ is centered in a few large departments; 14 pediatric departments receive 343 of the 572 NIH grants $(60 \%)$. By contrast, 66 of 120 pediatric departments have no (45) or 1 (21) NIH grants. Obstacles are identified and suggestions are offered for future (students and residents), beginning (fellows and assistant professors), established (associate and full professors) and women pediatric researchers. (Pediatr Res 19:593-598)

Pediatric research can use all the help it can get. Despite monumental scientific advances and proven cost benefits (eg, elimination of poliomyelitis), pediatric research (and other medical research), has undergone a growth arrest (1). If we are not vigilant, pediatric research can begin a period of failure to thrive. This essay addresses some ways to maintain its growth and development. I shall point out some advantages and disadvantages of pediatric research, discuss some financial aspects of 